\title{
The Competitive NMDA Antagonist CPP Blocks MK-801-Elicited Popping Behavior in Mice
}

Stephen I. Deutsch, M.D., Ph.D., Richard B. Rosse, M.D., Raine L. Riggs, B.A., Lee Koetzner, M.A., and John Mastropaolo, Ph.D.

In the current investigation, the ability of CPP \{3-(2carboxypiperazine-4-yl) propyl-1-phosphate to elicit mouse popping behavior in a manner similar to that of MK-801 was studied. Unlike MK-801, CPP (3.2-32 $\mathrm{mg} / \mathrm{kg})$ did not elicit any popping. The data show that a reduction in NMDA-mediated neural transmission alone is not sufficient to elicit popping behavior in mice. Moreover, pretreatment of mice with CPP attenuated MK-801's ability to elicit popping. These results suggest that popping requires the channel to be in the "active", or open, configuration and that it depends on MK-801's access and binding to its unique site in the hydrophobic channel domain. [Neuropsychopharmacology 15:329-331, 1996]
KEY WORDS: NMDA receptor; $M K-801$; Popping behavior; Phencyclidine; Schizophrenia

Phencyclidine (PCP) is a drug of abuse that precipitates a schizophreniform psychosis in susceptible individuals (Deutsch et al. 1989; Javitt and Zukin 1991). The psychosis precipitated by PCP shows both positive (e.g., hallucinations) and negative (e.g., social withdrawal) features of schizophrenia and is regarded as the best pharmacological model of this idiopathic psychotic disorder (Deutsch et al. 1989; Javitt and Zukin 1991). PCP is a noncompetitive antagonist of the N-methyl-Daspartic acid (NMDA) receptor complex, a class of glutamate-gated ion channel; it binds to a hydrophobic domain within the channel (Fagg 1987). PCP's action as

From the Department of Veterans Affairs Medical Center (SID, RBR, RLR, LK, JM), Psychiatry Service, Washington, DC, and the Georgetown University School of Medicine, Department of Psychiatry (SID; RBR), Washington, DC.

Address correspondence to: Stephen I. Deutsch, M.D., Ph.D., Department of Veterans Affairs Medical Center, Psychiatry Service, Room 3A154/116A, 50 Irving Street, N.W., Washington, DC 20422

Received August 14, 1995; revised October 12, 1995; accepted October 13, 1995. an "open-channel" blocker of the NMDA receptor complex and its ability to cause a drug-induced psychosis have led to the hypothesis that deficient glutamatergic transmission is involved in the pathophysiology of schizophrenia (Deutsch et al. 1989).

We have shown that MK-801, a high-affinity analogue of PCP, can elicit explosive episodes of jumping behavior in an outbred strain of mouse (Deutsch and Hitri 1993; Rosse et al. 1995; Deutsch et al., in press). The ability of conventional and atypical antipsychotic agents to attenuate this MK-801-elicited mouse "popping" behavior supports the development of this procedure as a preclinical screening paradigm for the identification of novel antipsychotic agents. Ideally, the paradigm could be used to identify potential medications that do not depend on the direct antagonism of dopamine at its receptor sites.

Competitive and noncompetitive NMDA receptor antagonists share common behavioral effects (e.g., they both antagonize rate-suppressing effects of NMDA); however, there are instances when this does not occur (Svensson et al. 1991; Winger et al. 1991; Cole et al. 1993). For example, in rhesus monkeys trained to discriminate between ketamine and saline, MK-801 shares 
discriminative stimulus properties with ketamine, whereas CGS 19755, a competitive antagonist, does not. These data suggest that antagonism caused by competitive and noncompetitive blockers may be distinguished from each other using functional behavioral measures. In the current investigation, we studied the effects of 3-(2-carboxypiperazine-4-yl)propyl-1-phosphate (CPP), a competitive NMDA receptor antagonist. We hypothesized that if popping resulted from a reduction in NMDA-mediated neurotransmission exclusively, CPP would share MK-801's ability to elicit mouse popping behavior. However, if the elicitation of popping specifically reflects MK-801's ability to access the channel, CPP would be devoid of any ability to elicit mouse popping behavior. If this was the case, we predicted that pretreatment with CPP, which results in fewer channels in the "active", or open, configuration, would actually attenuate the ability of MK-801 to elicit popping.

\section{METHODS}

\section{Animals}

Outbred NIH Swiss male mice weighing 20 to $35 \mathrm{~g}$ were obtained from the National Cancer Institute (Frederick, $\mathrm{MD}$ ) and housed (5 mice/cage) in hanging wire mesh cages. The animals were maintained on a 12-hour light / dark cycle, with free access to food and water. The mice were transported to the laboratory on the day of the ex- periment. Animals were weighed individually prior to drug injection, and automated assessment of motor behaviors.

\section{Drugs}

MK-801 (Dizolcipine) was purchased from Research Biochemical Incorporated (Natick, MA). MK-801 was administered intraperitoneally (IP) in a volume of 0.1 $\mathrm{mg} / 10 \mathrm{~g}$ body weight. CPP was also purchased from Research Biochemicals Incorporated and administered IP in a volume of $0.1 \mathrm{ml} / 10 \mathrm{~g}$ body weight. CPP was administered 15 minutes before the MK- 801 injection. Both drugs were dissolved in normal saline.

\section{Computerized Assessment of MK-801-Elicited Popping}

The automated system for measuring episodic popping is based on the detection and measurement of small vertical displacements of a platform related to animal movements. This has been described in detail in earlier work (Rosse et al. 1995).

The recording of MK-801-induced popping behavior was divided into two phases: a baseline period of $5 \mathrm{~min}$ utes (which followed the administration of a pretreatment of CPP 10 minutes earlier), and an outcome recording period of 30 minutes, which immediately
Figure 1. Mean ( \pm SEM) number of pops for groups of animals ( $n=12 /$ group) injected (IP) with either saline (squares) or $10 \mathrm{mg} / \mathrm{kg}$ of CPP (circles) 15 minutes prior to an injection (IP) of either saline (points above vehicle) or various doses of MK-801 (0.56-1.8 mg/kg).

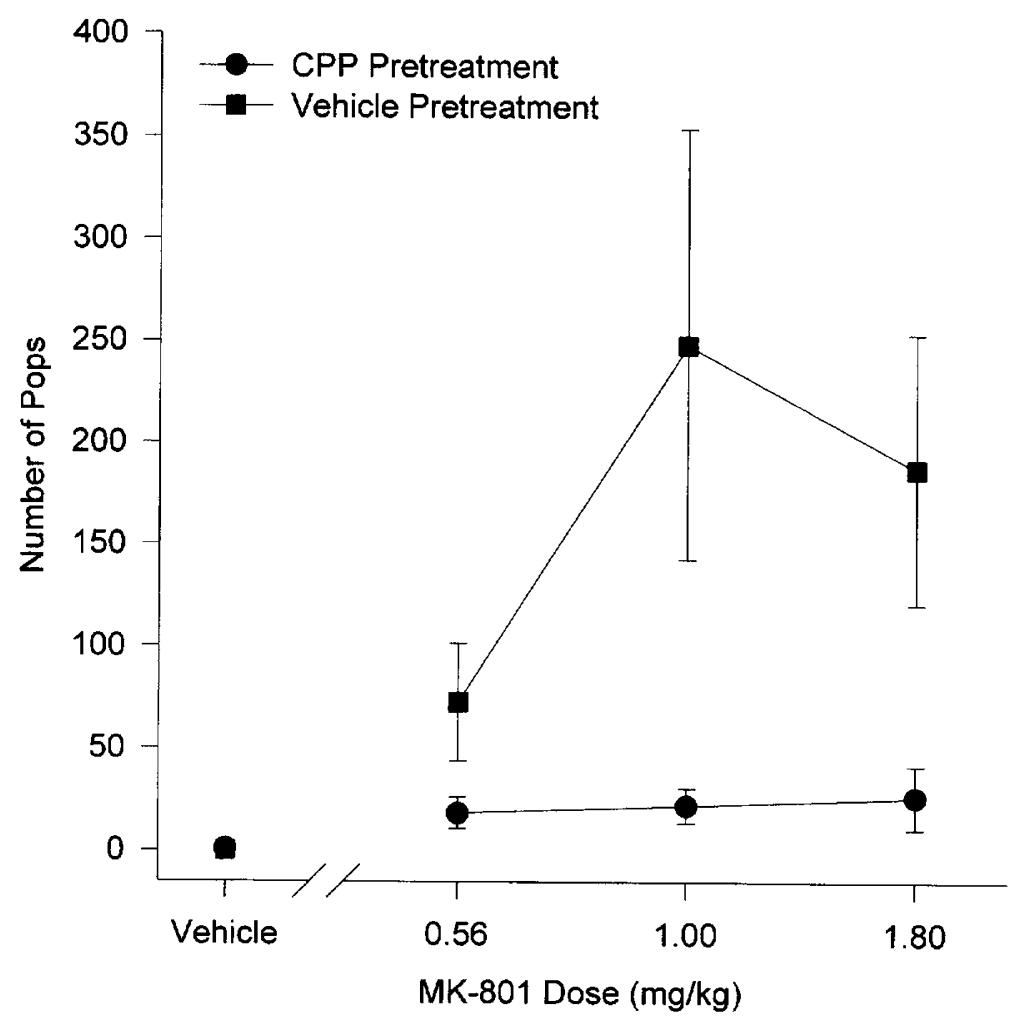


followed an injection of either normal saline (for the CPP dose-response curve generation) or MK-801.

\section{RESULTS}

CPP (3.2-32 $\mathrm{mg} / \mathrm{kg})$ did not elicit any popping and did not differ from saline [one-way analysis of variance (ANOVA), $\left(F_{5,63}=1.83, p=.12\right)$. Figure 1 shows the interaction of CPP and MK-801. The results of the twoway ANOVA reveal two significant main effects. The main effect for MK-801 $\left(F_{3,87}=3.82, p=.013\right)$ indicates that MK-801 elicited popping in a dose-dependent manner. The main effect for CPP $\left(F_{1,87}=12.7, p=\right.$ .0006 ) indicates that $10 \mathrm{mg} / \mathrm{kg}$ of CPP significantly attenuated MK-801's ability to elicit popping.

\section{DISCUSSION}

The data from the experiment with CPP alone support the notion that a reduction in NMDA-mediated neural transmission alone is not sufficient to elicit popping behavior in mice. Moreover, the results from the interaction of CPP and MK-801 suggest that the open configuration of the NMDA-associated ionophore is necessary, but not sufficient, to elicit popping. The results indicate that popping is a consequence of MK-801's access and binding to its unique site in the hydrophobic channel domain. Finally, if endogenous "open-channel" blocking ligands of the NMDA receptor complex exist (e.g., "sigmaphins") and are abnormally elevated in patients with schizophrenia, the data suggest that competitive antagonism of the NMDA receptor complex could have desirable therapeutic effects in some circumstances ( $\mathrm{Su}$ et al. 1986; Contreras et al. 1987).

\section{ACKNOWLEDGMENT}

This work was supported by a grant from the Department of Veterans Affairs.

\section{REFERENCES}

Cole BJ, Klewer M, Jones GH, Stephens DN (1993): Contrasting effects of the competitive NMDA antagonist CPP and the noncompetitive NMDA antagonist MK-801 on performance of an operant delayed matching to position task in rats. Psychopharmacology 111:465-471

Contreras PC, DiMaggio DA, O'Donohue TL (1987): An endogenous ligand for the sigma opioid binding site. Synapse 1:57-61

Deutsch SI, Hitri A (1993): Measurement of an explosive behavior in the mouse, induced by MK-801, a PCP analogue. Clin Neuropharmacol 16(3): 251-257

Deutsch SI, Mastropaolo J, Schwartz BL, Rosse RB, Moirhisa JM (1989): A "glutamatergic hypothesis" of schizophrenia: Rationale for pharmacotherapy with glycine. Clin Neuropharmacol 12:1-13

Deutsch SI, Rosse RB, Paul SM, Tomasino V, Koetzner L, Morn CB, Mastropaolo J (in press): 7-Nitroindazole and methylene blue, inhibitors of neuronal nitric oxide synthase and NO-stimulated guanylate cyclase, block MK801 elicited behaviors in mice. Neuropsychopharmacology

Fagg GE (1987): Phencyclidine and related drugs bind to the activated N-methyl-D-aspartate receptor-channel complex in rat brain membranes. Neurosci Lett 76:221-227

Javitt DC, Zukin SR (1991): Recent advances in the phencyclidine model of schizophrenia. Am J Psychiatry 148:13011308

Rosse RB, Mastropaolo J, Sussman DM, Koetzner L, Morn CB, Deutsch SI (1995): Computerized measurement of MK-801-elicited popping and hyperactivity in mice. Clin Neuropharmacol 18 (5):448-457

Su T-P, Weissman AD, Yeh S-Y (1986): Endogenous ligands for sigma opioid receptors in the brain ("sigmaphin"): evidence from binding assays. Life Sci 38:2199-2210

Svensson A, Pileblad E, Carlsson A (1991): A comparison between the non-competitive NMDA antagonist dizocilipine (MK-801) and the competitive NMDA antagonist D-CCPene with regard to dopamine turnover and locomotor-stimulatory properties in mice. J Neural Transm [GenSect] 85:117-129

Winger G, France CP, Woods JH (1991): Comparison of CGS 19755 and phencyclidine-like compounds. In Meldrum BS, Moroni F, Simon RP, Woods JH (eds), Excitatory Amino Acids. New York, Raven, pp 539-545 